Marta García-Queiruga ${ }^{1}$ Begoña Feal Cortizas' Fernando Lamelo Alfonsin ${ }^{2}$ Sonia Pertega Diaz ${ }^{3}$ Isabel Martín-Herranz'

\section{Continuous infusion of antibiotics using elastomeric pumps in the hospital at home setting}

'Servicio de Farmacia. Complejo Hospitalario Universitario A Coruña. Spain

${ }^{2}$ Servicio de Hospitalización a Domicilio. Complejo Hospitalario Universitario A Coruña.

${ }^{3}$ Unidad de Epidemiología Clínica y Bioestadística. Complejo Hospitalario Universitario A Coruña.

Article history

Received: 15 October 2020; Revision Requested: 23 November 2020; Revision Received: 12 December 2020; Accepted: 11 January 2021; Published: 16 March 2021

\section{ABSTRACT}

Introduction. To describe the avoided costs and to analyze the effectiveness of intravenous antibiotic treatment in continuous perfusion in patients at Hospital at Home Units (HHU) administered using elastomeric infusion pumps (EIP) prepared in a Hospital Pharmacy Service (HPS).

Materials and methods. Retrospective observational study of the number and type of EIP prepared in the HPS and of the treated patients. Study period: January 2017-December2018. Analyzed data: demographic data of patients, location of infection, responsible microorganism, medication and type of EIP, dose and duration of treatment and its effectiveness in terms of cure or non-cure or patient's death. Economic valuation considering: costs of EIP, nursing time needed for preparation and cost of HHU care.

Results. A total of 1,688 EIP to treat 102 patients resulted in 106 episodes of outpatient treatment of parenteral antibiotic therapy (OPAT) for 1,409 days, thereby avoiding 1,409 days of hospital admission. A total of $59.8 \%$ of the patients were men and the mean age was $70.5 \pm 17$ years. A $31.1 \%$ and $68.9 \%$ of the cases were empirical and pathogen-directed treatments, respectively. The most used antimicrobials were piperacillin/ tazobactam $(42.7 \%)$, ceftazidime $(24.5 \%)$, meropenem (19.8\%), ceftolozane/tazobactam (2.8\%), and cloxacillin (1.9\%). Mean duration of treatment was $13.29 \pm 8.60$ days. Location of infection: respiratory $(42.5 \%)$, urinary $(17.9 \%)$, skin and soft tissue (12.3\%), bacteraemia (11.3\%), osteomyelitis (7.5\%), abdominal (3.8\%) and $4.7 \%$ in other locations. The cure rate was $84 \%$. Total avoided cost: $580,788.28 €$ in the 24 months studied.

Correspondence:

Marta Garcia-Queiruga.

Servicio de Farmacia. Complejo Hospitalario Universitario A Coruña.

C/ As Xubias 84, 1a planta. 15006 A Coruña. Spain

Phone: +34 981176480

E-mail: marta.garcia.queiruga@sergas.es
Conclusion. This program represents very important economic savings for the health system, and the effectiveness of the antibiotic treatment has not been compromised.

Key words: Elastomeric infusion pumps, Hospital at Home Units, OPAT.

\section{Utilización de infusores elastoméricos de antibióticos en Hospitalización a Domicilio}

\section{RESUMEN}

Objetivo. Describir los costes evitados y analizar la efectividad del tratamiento con antibióticos por vía intravenosa en perfusión continua en pacientes en unidades de Hospitalización a Domicilio (HD) administrados con bombas de infusión elastoméricas (BIE) preparadas en un Servicio de Farmacia Hospitalaria (SFH).

Método. Estudio observacional retrospectivo del número y tipo de BIE preparados en el SFH y pacientes tratados entre enero 2017 y diciembre 2018. Los datos analizados fueron: datos demográficos de pacientes, localización de la infección, microorganismo, medicación y tipo de $\mathrm{BIE}$, dosis y duración del tratamiento y efectividad en términos de curación o no curación o muerte. Valoración económica: coste de BIE, tiempo de enfermería necesario para la preparación y coste de la atención en HD.

Resultados. Se analizaron 1.688 BIE preparados para tratar 102 pacientes que resultaron en 106 episodios de tratamiento ambulatorio durante 1.409 dias, evitando así 1.409 dias de ingreso hospitalario. El 59,8\% de los pacientes

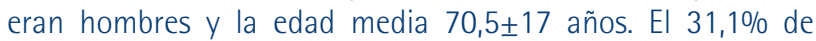
los tratamientos fueron empíricos versus $68,9 \%$ dirigidos por patógeno. Los antimicrobianos más empleados fueron piperacilina-tazobactam $\quad(42,7 \%)$, ceftazidima $(24,5 \%)$, meropenem (19,8\%), ceftolozano-tazobactam $(2,8 \%)$ y cloxacilina $(1,9 \%)$. La duración media del tratamiento fue de 
$13,29 \pm 8,60$ días. Localización de la infección: respiratorias $(42,5 \%)$, urinarias $(17,9 \%)$, piel y partes blandas $(12,3 \%)$, bacteriemias (11,3\%), osteomielitis $(7,5 \%)$, abdominales $(3,8 \%)$ y un 4,7\% en otras localizaciones. La tasa de curación del $84 \%$. El coste total evitado fue de 580.788,28€ durante los 24 meses de estudio.

Conclusiones. Este programa representa un ahorro económico muy importante para el sistema de salud, y la efectividad del tratamiento con antibióticos no se ha visto comprometida.

PALABRAS CLAVE: Infusores elastoméricos, hospitalización a domicilio, TADE.

\section{INTRODUCTION}

The outpatient treatment of parenteral antibiotic therapy (OPAT) is defined as the administration of parenteral treatments to patients not admitted at hospital, with duration of at least two doses on different days. It constitutes alternative care to hospital admission in patients with infectious pathology and in Spain it is usually done by the Hospital at Home Units (HHU).

The administration of intravenous antimicrobials at home was first described in 1974 in children with cystic fibrosis [1], and has grown rapidly as an alternative to hospitalization. Several factors have contributed to this growth, such as the containment of costs, the development of antimicrobials that can be administered once or twice a day, advances in vascular access, development of new administration systems, acceptance and/or patients' and health professionals' preference, among others [2].

Recent systematic reviews have described more than 60,000 episodes of OPAT, without finding differences in the duration of treatment or adverse effects compared with hospitalized patients. Another favorable aspect identified by patients is the perception of greater well-being when staying at home instead of hospitalisation and the increase in free time and autonomy [3].

A large variety of infections have been treated with OPAT, these being the most frequent complicated soft tissue infections, namely osteomyelitis, complicated urinary tract infection, endocarditis and bacteremia [4].

As key points in the OPAT, a basic requirement is a health team with adequate experience, such as the HHU, which allows outpatient treatment and control of serious and complex situations, such as infectious processes, which often require an extension of the hospital stay, requiring long intravenous treatments without an effective oral alternative. Without these, HHU patients should remain hospitalized [5]. Another important aspect is the design of devices for infusion, such as portable programmable pumps or elastomeric infusion pumps (EIP), which allow effective and safe infusion of most antimicrobials. The EIP offer, as additional advantages, the ease of handling; they are light, silent and they do not require an external power supply for their operation, allowing total mobility of the patient and facilitating their return to work, family and social life. The main limitations are predetermined flows, restrictions in the diluent, variability in the duration of the infusion, absence of warning alarms in case of occlusions and stability data of home conditions [6]. It is important to know that the flow rate of the EIP can be affected by several factors such as the variation in temperature, the position it is placed during its administration with respect to the patient's vascular access, viscosity, filling volume and storage temperature. Differences in flow rate have been described between clinical practices in relation to calibration conditions of up to 50\%. This could cause a lack of clinical response or prolonged or too rapid duration of infusions [7].

Another facilitator aspect is the administration of betalactam antibiotics in prolonged perfusion. In observational studies clinical benefit is shown in certain situations, without adverse effects.

It has been seen that the emergence of resistance to antibiotics such as piperacillin/tazobactam or meropenem was not related to the mode of administration [8].

The preparation of EIP in laminar flow cabinets is essential to guarantee the absence of microbiological contamination when preparing doses for several days. In addition, a shorter time of dose preparation has been demonstrated in the pharmacy service compared to nursing units [9]. The involvement of the pharmacy service is essential in aspects such as: antibiotic stability times, adverse effects, interactions, pharmacokinetic monitoring, dilution volumes depending on the maximum possible concentration, stability at room temperature or refrigerated, selection of the most suitable device for the patient, registration of incidents, etc. [10].

The central axis of the OPAT process is the patient, and both they and their caregiver must be properly informed, know the management of the infusion technique in case of selfadministration, and understand the benefits, risks and possible complications of OPAT, as well as recognize the complications derived and the action required in case of occurrence. This aspect is very relevant since some authors found that OPAT produces anxiety in patients [11].

The aim of this paper is to describe the avoided costs and to analyze the effectiveness of intravenous antibiotic treatment in continuous perfusion in patients with $\mathrm{HHU}$ administered using EIP prepared in the Hospital Pharmacy Service (HPS).

\section{MATERIAL AND METHODS}

A retrospective observational study was conducted on the number and type of EIP for continuous perfusion of antibiotics prepared in a HPS and of the patients treated during the period January 2017-December 2018 by HHU.

All the patients who were treated with antibiotics administered intravenously in continuous perfusion by EIP and in the care of the HHU were included in the study. The main criterion for the administration of antibiotics was that the patient did not have a caregiver with sufficient capacity 
or availability of time for the administration of the antibiotic according to the corresponding time schedule.

Patients who received OPAT using EIP in intermittent infusion and those who were not managed by the HHU were excluded from the study.

Demographic data of the treated patients, localization of the infection, responsible microorganism, medication and type of EIP used, dose and duration of the treatment and its effectiveness in terms of cure of the infection, non-cure or patient's death have been analyzed.

For the economic valuation, several items have been considered: costs of the EIP, nursing time needed for their preparation and cost of HHU care, which includes cost of transport and cost of all sanitary care.

These data have been compared with the avoided cost corresponding with the days of hospital admission.

The cost of the medication has not been included since it was considered the same whether the patient remains hospitalized or goes home. Neither the physician nor pharmacist's work time has been analyzed considering it equivalent in either hospital admissions or management by HHU.

As the basis for the calculation of hospital admission costs, the regional normative has been considered [12], according to which a day of home hospitalization cost $€ 80.70$, and the cost per hospital admission day is $€ 528.95$.

In addition, according to the regional normative [13] to estimate the costs of nursing work needed for the preparation of the EIP, it has been considered that $€ 15.81$ per hour is around the cost incurred and it has been estimated that a nurse prepares an average of 10 EIP per hour.

The EIP used were manufactured by Baxter Healthcare Corporation for those of 24-hour duration (120 ml volume and flow rate of $5 \mathrm{ml} / \mathrm{h}$; with $240 \mathrm{ml}$ volume and a flow rate of $10 \mathrm{ml} / \mathrm{h}$ ), and Dosi-Fuser Leventon $(240 \mathrm{~mL}$ volume and flow rate of $20 \mathrm{ml} / \mathrm{h}$ ). Stability information provided was based on stability data of each medication in the refrigerator and at room temperature. The HHU nurse goes daily to the patient's home to change the EIP.

The unit cost of the EIP was $€ 29.70$ for the 12 -hour devices (2 required per day: daily cost of treatment $€ 59.40$ ), $€ 32.89$ for the $120 \mathrm{ml} / 24$-hour devices and $€ 25.63$ for the $240 \mathrm{ml} / 24$-hour devices, therefore, the average cost per day of treatment with EIP of around $€ 39.30$ (range $€ 25.63-59.40$ / day).

The clinical data have been obtained from the patient's electronic medical records at the end of treatment and 30 days after. The cure rate, hospital readmission, relapse of the infection and cases of death have been evaluated.

A descriptive analysis of the collected data was carried out. The qualitative variables are described as frequencies and percentages, the quantitative variables as mean, standard deviation, median and range. The cure rate according to the treatment received was compared with the chi-squared test, and the duration of treatment using the Mann-Whitney test. Average savings per patient were compared using Wilcoxon's signed Rank test.

\section{RESULTS}

A total of 1,688 EIP were prepared to treat 102 patients, which resulted in 106 episodes of OPAT for 1,409 days. These avoided 1,409 days of hospital admission.

Four patients received two cycles of antibiotic treatment during this period.

168.8 hours of nursing work were required in the pharmacy service for preparing the EIP in aseptic and validated conditions.

Economic results. The antibiotics prepared in EIP, dose, type of device, number of patients treated, days of treatment and costs of EIP and nursing work are shown in Table 1.

The cost of hospitalization at home was $€ 113,706.3$ and the cost of the 1,688 EIP, not considering the medication, was $€ 48,127.25$.

The estimated cost of 1 month of antibiotic treatment when performed by hospital admission was $€ 15,867.37$, and by HHU it was $€ 1,024.64$. Such difference between both modalities corresponds mostly by the great difference of the value of the stay in both services.

The estimated avoided cost for 1,409 days of hospital admission was $€ 745,290.55$.

Regarding these data, it was estimated that the total avoided cost when performing OPAT using EIP instead of with the patient admitted, was $€ 580,788.28$ for the 24 months of the study period.

The mean cost per patient in HHU was found to be 1,696.4 $\pm 1,284.4$ euros, with a median of $€ 1,419.4$ and a range of $€ 318.3$ to $9,548.3$. The mean cost per patient in hospital admission would be 7,031.0 \pm 4551.0 euros, with a median of $€ 6,347.4$, and a range of $1,057.9$ to $32,365.9$ euros.

Thus, the average savings per patient would be 5,334.6 \pm 3,690.6 euros, with a median of 4,630.3 euros (range: -973.0; 25,677.3). The significance value (Wilcoxon's signed Rank test, $\mathrm{p}<0.001)$.

Clinical results. Demographic and clinical data of the patients who received OPAT with EIP during this period are detailed in Table 2.

$59.8 \%$ of the patients were men and the mean age was $70.5 \pm 17$ years (range 19-100 years).

In $31.1 \%$ of the treatments performed were empirical versus $68.9 \%$ with directed treatment after identifying the microorganisms responsible for the infection.

The antimicrobials used were piperacillin/tazobactam in $42.7 \%$ of cases, meropenem in $19.8 \%$, ceftazidime in $24.5 \%$, ceftolozane/tazobactam in $2.8 \%$ and cloxacillin in $1.9 \%$ 
followed by ampicillin, aztreonam, cefazolin and cefepime in $0.9 \%$ of cases each.

For the group of empirically treated cases, $60.6 \%$ of the treatments were performed with piperacillin/tazobactam, $27.3 \%$ with meropenem and $12.1 \%$ with ceftazidime.

Regarding the location of the infection, $42.5 \%$ of the cases were respiratory infections, followed by $17.9 \%$ urinary infections, $12.3 \%$ skin and soft tissue infections, 11.3\% bacteremia, $7.5 \%$ osteomyelitis, 3.8\% abdominal infections and $4.7 \%$ other locations.

The rate of cases treated empirically corresponds to $66.7 \%$ of respiratory infections, 9.1\% of skin and soft tissue infections, 6.1\% of urinary, abdominal and other infection locations, as well as 3\% of bacteremia and osteomyelitis.

In relation to the microorganisms responsible for the infection, Pseudomonas aeruginosa was isolated in a microbiological culture in $40.6 \%$ of the cases, Klebsiella pneumoniae OXA-48 in 5.7\%, Klebsiella spp. in 1.9\%, Grampositive cocci in $11.3 \%$, and other Gram-negative bacilli in $9.4 \%$ of cases.

In relation to the duration of treatment, the mean number of treatment days was $13.29 \pm 8.60$ (range 2-61 days). In the analysis by groups, for the empirically treated cases, the days of treatment averaged $11.31 \pm 6.90$ days, while in the group of targeted treatments it was $14.18 \pm 9.17$ days. There were no statistically significant differences in the duration of treatment for cases treated empirically versus directed $(p=0.75)$. Although the respiratory infection required fewer days of treatment compared to the rest of the infections (11.9 vs 19.1), no statistically significant differences were found $(p=0.21)$.

Depending on the location of the infection, the duration of treatment is detailed in Table 3. Osteomyelitis required a longer period of antibiotic treatment, with a mean of 24.87 \pm 17.19 days of treatment, followed by skin and soft tissue infections with $17.15 \pm 9.34$ days, other locations with 13.90 \pm 6.94 days, abdominal infections with $14.12 \pm 6.78$ days and respiratory infections with $10.55 \pm 5.21$ days, and urinary infections with $11.36 \pm 7.03$ days of treatment.

Considering the therapeutic efficacy, a cure rate of $84 \%$ has been observed. 3.8\% of cases required hospital readmission due to poor evolution, 2.8\% required treatment change and 9.4\% ended in death (two cases due to poor outcomes of the infectious process in elderly patients with multiple pathologies, one due to ovarian cancer and one due to chronic lymphatic leukaemia). It was observed that there were clinical differences in mortality in the group of patients aged 79 years or older (nine patients died), however, no statistically significant differences were found in the age group $<70$ years.

When comparing empirically treated patients with pathogen-directed treated, no statistically significant differences were observed in terms of cure ( $p=0.867)$.

\section{\begin{tabular}{l|l} 
Table 1 & Elastomeric infusion pumps for continuous perfusion prepared in 2017 and 2018.
\end{tabular}}

\begin{tabular}{|c|c|c|c|c|c|c|}
\hline Antimicrobial & Dose & EIP type (volume/duration) & № patients & Days of treatment & EIP cost $(€)$ & Nursing work time $(h) / \operatorname{cost}(€)$ \\
\hline Ampicillin & $6 \mathrm{~g} / 12 \mathrm{~h}$ & $240 \mathrm{ml} / 12 \mathrm{~h}$ & 1 & 9.5 & 564.30 & $1.9 / 30.04$ \\
\hline Aztreonam & $6 \mathrm{~g} / 24 \mathrm{~h}$ & $240 \mathrm{ml} / 24 \mathrm{~h}$ & 1 & 7 & 179.41 & $0.7 / 11.07$ \\
\hline Cefazolin & $3 g / 24 h$ & $120 \mathrm{ml} / 24 \mathrm{~h}$ & 1 & 13 & 427.57 & $1.3 / 20.55$ \\
\hline Cefepime & $8 \mathrm{~g} / 24 \mathrm{~h}$ & $120 \mathrm{ml} / 24 \mathrm{~h}$ & 1 & 18 & 592.02 & $1.8 / 28.46$ \\
\hline \multirow[t]{2}{*}{ Ceftazidime } & $6 \mathrm{~g} / 24 \mathrm{~h}$ & $120 \mathrm{ml} / 24 \mathrm{~h}$ & 24 & 304 & 9998.56 & $30.4 / 480.62$ \\
\hline & $8 \mathrm{~g} / 24 \mathrm{~h}$ & $240 \mathrm{ml} / 24 \mathrm{~h}$ & 2 & 39 & 999.57 & $3.9 / 61.66$ \\
\hline \multirow[t]{2}{*}{ Ceftolozane-tazobactam } & $6 \mathrm{~g} / 24 \mathrm{~h}$ & $240 \mathrm{ml} / 24 \mathrm{~h}$ & 1 & 21 & 538.23 & $2.1 / 33.20$ \\
\hline & $3 \mathrm{~g} / 12 \mathrm{~h}$ & $240 \mathrm{ml} / 12 \mathrm{~h}$ & 2 & 22 & 1306.8 & $4.4 / 69.56$ \\
\hline Cloxacillin & $12 \mathrm{~g} / 24 \mathrm{~h}$ & $240 \mathrm{ml} / 24 \mathrm{~h}$ & 2 & 31 & 794.53 & $3.1 / 49.01$ \\
\hline \multirow[t]{3}{*}{ Meropenem } & $1 \mathrm{~g} / 12 \mathrm{~h}$ & $240 \mathrm{ml} / 12 \mathrm{~h}$ & 1 & 245 & 14553 & $49 / 774.69$ \\
\hline & $1,5 \mathrm{~g} / 12 \mathrm{~h}$ & & 6 (2 patients received 2 cycles) & & & \\
\hline & $3 \mathrm{~g} / 12 \mathrm{~h}$ & & 12 & & & \\
\hline \multirow[t]{4}{*}{ Piperacillin-tazobactam } & $16 \mathrm{~g} / 24 \mathrm{~h}$ & $240 \mathrm{ml} / 24 \mathrm{~h}$ & 3 & 677 & 17351.51 & $67.7 / 1070.34$ \\
\hline & $12 \mathrm{~g} / 24 \mathrm{~h}$ & & 42 (2 patients received 2 cycles) & & & \\
\hline & $9 \mathrm{~g} / 24 \mathrm{~h}$ & $120 \mathrm{ml} / 24 \mathrm{~h}$ & 2 & 25 & 822.25 & $2.5 / 39.52$ \\
\hline & $6 \mathrm{~g} / 24 \mathrm{~h}$ & & 1 & & & \\
\hline TOTAL & & & 102 & 1,409 & $48,127,25$ & $168.8 / 2,668.72$ \\
\hline
\end{tabular}




\begin{tabular}{|c|c|c|}
\hline Table 2 & Demographic and clinical data & \\
\hline \multirow{2}{*}{\multicolumn{2}{|c|}{ Age }} & Mean $70,5 \pm 17$ years (range $19-100$ ) \\
\hline & & Median 73,0 years \\
\hline \multicolumn{2}{|l|}{ Sex } & № cases \\
\hline \multicolumn{2}{|l|}{ Men } & 61 \\
\hline \multicolumn{2}{|l|}{ Women } & 45 \\
\hline \multicolumn{2}{|c|}{ Location of the infection } & № cases \\
\hline \multicolumn{2}{|c|}{ Bacteraemia } & 12 \\
\hline \multicolumn{2}{|c|}{ Skin and soft tissue infection } & 13 \\
\hline \multicolumn{2}{|c|}{ Abdominal infection } & 4 \\
\hline \multicolumn{2}{|c|}{ Respiratory infection } & 45 \\
\hline \multicolumn{2}{|c|}{ Urinary infection } & 19 \\
\hline \multicolumn{2}{|c|}{ Osteomyelitis } & 8 \\
\hline \multicolumn{2}{|c|}{ Endocarditis } & 2 \\
\hline \multicolumn{2}{|c|}{ Central nervous system infection } & 1 \\
\hline \multicolumn{2}{|l|}{ Other } & 3 \\
\hline \multicolumn{2}{|c|}{ Pathogen-directed treatments (bacteria isolated in microbiologic culture) } & $N^{0}$ cases with isolations \\
\hline \multicolumn{2}{|c|}{ Klebsiella pneumoniae 0XA-48 } & 5 \\
\hline \multicolumn{2}{|c|}{ Klebsiella spp. } & 2 \\
\hline \multicolumn{2}{|c|}{ Pseudomonas aeruginosa } & 43 \\
\hline \multicolumn{2}{|c|}{ Other Gram-negative bacilli (Proteus spp., Morganella morganii, Enterococcus spp., Escherichia coli) } & 10 \\
\hline \multicolumn{2}{|c|}{ Gram-positive cocci (Staphylococcus spp. and Streptococcus spp.) } & 12 \\
\hline \multicolumn{2}{|c|}{ Empirical treatments ( ${ }^{\circ}$ cases) } & 33 \\
\hline
\end{tabular}

\section{DISCUSSION}

This article describes the economic and clinical results of patients who received OPAT in continuous perfusion, using EIP managed by HHU. We have selected the administration of the antibiotic in prolonged perfusion (infusion in 24 hours at constant flow rate) for various reasons, among which it stands out that it allows reconciliation of the placement of the EIP and administration of the antibiotic with the visit of the HHU staff to the domicile. The 24-hour administration allows the nursing staff to change the device without requiring the patient's or family's intervention. In addition, a meta-analysis has shown that continuous perfusion of carbapenems and piperacillin/tazobactam was associated with lower mortality when compared to intermittent perfusion administration [14], and in the case of beta-lactams, reaching higher plasma concentrations than intermittent administration [15].

Although the use of ampicillin in the outpatient setting has been traditionally avoided due to its short half-life and short stability in solution, recent data support the safe and effective administration by continuous infusion in the community [16-18]. In addition, for ampicillin, the purpose of continuous administration in our patients is justified thanks to the greater comfort for the patient and also allows the patient to be admitted to the $\mathrm{HHU}$, since with the usual interval of administration every 4 or 6 hours it would not be possible.

The preparation of the EIP was performed in all cases centrally in the pharmacy service under aseptic conditions, in order to prevent potential harm to the patient due to microbiological contamination, excessive content of endotoxins in the mixture, or errors in the preparation. These aspects are especially relevant because the medication is dispensed to be administered in the patient's home [19].

For ampicillin and ceftolozane/tazobactam for the 24-hour infusion, it was necessary to use two EIP a day of 12 hours' duration for reasons of stability related with concentration. In the case of meropenem, two EIP of 12 hours' duration were used every day due to the instability of meropenem at room temperature [20].

Regarding the economic results and assuming that the duration of the treatment is the same whether the patient was admitted to the hospital or in HHU, the use of home EIP in the study period of 24 months avoided the use of 1409 hospital bed days, which meant a decrease in costs for the health 


\begin{tabular}{l|ccc}
\hline Table 3 & \multicolumn{3}{|c}{$\begin{array}{l}\text { Duration of antibiotic treatment at } \\
\text { home considering the location of the } \\
\text { infection. }\end{array}$} \\
\hline Location of infection & Mean (days) & Standard deviation & Median \\
\hline Respiratory & 10.55 & 5.21 & 10.00 \\
\hline Bacteraemia & 14.16 & 6.78 & 14.00 \\
\hline Skin and soft tissue & 17.15 & 9.34 & 16.00 \\
\hline Urinary & 11.37 & 7.30 & 10.00 \\
\hline Abdominal & 14.12 & 6.78 & 11.75 \\
\hline Osteomyelitis & 24.87 & 17.09 & 20.00 \\
\hline Other & 13.90 & 6.94 & 15.00 \\
\hline Total & 13.29 & 8.60 & 12.00 \\
\hline
\end{tabular}

system of $77.92 \%$. The great difference between the costs per day of hospitalization compared to stay at home (€528.95 versus $€ 80.70$ respectively) stands out. González Ramallo et al. found that the cost of each episode of hospital at home hospitalization was $80 \%$ less than that of hospitalization [21], which is consistent with our series. Some authors have argued that OPAT could reduce health costs mainly due to the reduction of days of hospital stay. A reduction of 47\% in hospital costs has been found, and other authors have identified a saving of 7394 days of hospital stay over a period of 44 months, which was related to potential savings of 1.5 million pounds $[22,23]$. The number of bed days saved represents an additional advantage for the hospital by not blocking beds, or the need for using measures to prevent the transmission of nosocomial infections often caused by multiresistant microorganisms that require the patient's isolation.

Concerning the type of infection, these results show that many infectious processes can be treated in the context of $\mathrm{HHU}$, the most frequent being, in our case, respiratory and urinary infections (45\% and 17.6\%) which agrees with the research of Mirón-Rubio et al., where these infections represent 72\% of their series [24] and in contrast with other publications in which bone infection and skin and soft tissue infections were the most frequent [25]. Respiratory infection presents a more unpredictable clinical course, and an increased risk of complications, which is why close monitoring by HHU professionals is necessary, closely assessing patients.

The average age of our patients was 70.5 years, which reflects an ageing population group, with $35 \%$ of patients aged 80 years or older, older than the cohorts studied in other research [26]. The therapeutic success in curing the infectious process was $84 \%$, with a readmission rate at 30 days of $3.4 \%$. A mortality of 9.4\% (10 patients) has been observed, although in three patients this was due to complications of their basal disease and the rest due to important comorbidities. Nine of the 10 deaths occurred in the population group over 70 years. Other authors have described cure rates ranging from $72.5 \%$ to $95 \%$ [25]. In a recently published study also using
EIP in continuous perfusion [27], 92\% cure rates are described. However, the average age of this group was 59 years, which probably indicates a population without multiple comorbidities and absence of multi-resistant bacteria.

There is a trend towards an increase in the number of patients and the number of ElPs prepared in 2017 compared to 2018 (39 patients, 579 infusers versus 67 patients and 1109 infusers respectively), which gives an idea of the satisfaction of the health staff and the good operation of the procedure.

Some limitations of this study are that the patient or the home care team has not evaluated the satisfaction of the procedure and also that neither catheter complications in hospital admission nor in HHU have been evaluated. Another limitation could be that for the calculation of costs of the health system, the cost of readmission and retreatment has not been evaluated.

As a conclusion of this work, we can say that this procedure represents a very important economic saving for the health system, and the effectiveness of the antibiotic treatment has not been compromised.

The OPAT in continuous perfusion and the collaboration of the Pharmacy Service and Hospital at Home Units allows a type of safe, effective and efficient health care, allowing the patient to achieve a more adequate recovery with his family and social environment, avoiding complications of a diverse nature that the conventional hospital admission supposes.

\section{FUNDING}

None to declare.

\section{CONFLICTS OF INTEREST}

The authors declare that they have no conflicts of interest

\section{REFERENCES}

1. Rucker RW, Harrison GM. Outpatient intravenous medications in the management of cystic fibrosis. Pediatrics. 1974;54:358-60. PMID: 4213282

2. Tice AD. Practice Guidelines for outpatient parenteral antimicrobial therapy. Clin Infect Dis. 2004;38:1651-72. doi: 10.1086/420939

3. Mitchell E, Czoski Murray C, Meads D, Minton J, Wright J, Twiddy M. Clinical an cost-effectiveness, safety and acceptability of community intravenous antibiotic service models: CIVAS systematic review. BMJ Open 2017;7:e013560. doi:10.1136/ bmjopen-2016-013560

4. Chapman AL. Outpatient parenteral antimicrobial therapy. BMJ. 2013;346:1585. doi: 10.1136/bmj.f1585

5. González Ramallo V, Valdivieso B, Ruiz V. Hospitalización a Domicilio. Med Clin. 2002;118:659-64. doi: 10.1016/s00257753(02)72488-3

6. Baxter Corporation. Baxter-Elastomeric-Pumps-Clinician-Guide 
2011. [Access 13 December 2019] Available from: https:///www. capca.ca/wp-content/uploads/Baxter-Elastomeric-PumpsClinician-Guide11.pdf.

7. Hobbs JG, Ryan MK, Ritchie B, Sluggett JK, Sluggett AJ, Ralton $L_{\text {, et }}$ al. Protocol for a randomised crossover trial to evaluate patient and nurse satisfaction with electronic and elastomeric portable infusion pumps for the continuous administration of antibiotic therapy in the home: the Comparing Home Infusion Devices (CHID) study. BMJ Open 2017;7:e016763. doi:10.1136/ bmjopen-2017-016763

8. Dhaese SAM, De Kezel M, Callant M, Boelens J, De Bus L, Depuydt $P$, et al. Emergence of antimicrobial resistance to piperacillin/ tazobactam or meropenem in the ICU: Intermittent versus continuous infusion. A retrospective cohort study. J Crit Care. 2018; 47:164-168. doi: 10.1016/j.jcrc.2018.07.003

9. Cuesta-Lopez I, Sánchez-Cuervo M, Candela-Toha A, BenedíGonzález J, Bermejo-Vicedo T. Impact of the implementation of vasoactive drug protocols on costs in the treatment of critically ill patients. Farm Hosp. 2018; 42(2):62-67. doi: 10.7399/fh.10844

10. Ruiz-Campuzano $M$, García-Vázquez $E_{1}$ Hernández-Roca JJ, Gómez-Gómez J, Canteras-Jordana M, Mené-Fenor E, et al. Design and implementation of an outpatient parenteral antimicrobial therapy program in primare care: the experience at a second level hospital. Rev Esp Quimioter. 2017;30(1):19-2730. PMID: 27898208

11. Bamford KB, Desai M, Aruede MJ, Lawson W, Jacklin A, Dean Franklin $B$, et al. Patient's views and experience of intravenous and oral antimicrobial therapy: room for change. Injury. 2011;42(Suppl 5):S24:S2742. doi: 10.1016/S0020-1383(11)70129-2

12. DECRETO 56/2014 de 30 de abril, por el que se establecen las tarifas de los servicios sanitarios prestados en los centros dependientes del Servicio Gallego de Salud y en las fundaciones públicas sanitarias. [Access 13 December 2019] Available at: https://www.xunta.gal/ dog/Publicados/2014/20140521/AnuncioC3K1-140514-0001_ es.html

13. ORDEN de 10 de febrero de 2017 por la que se dictan instrucciones sobre la confección de nóminas del personal al servicio de la Administración autonómica para el año 2017 [Access 13 December 2019] Available at: https://www.xunta.gal/dog/ Publicados/2017/20170215/AnuncioCA01-100217-0004_es.html

14. Falagas ME, Tansarli GS, Ikawa K, Vardakas KZ. Clinical outcomes with extended or continuous versus short-term intravenous infusion of carbapenems and piperacillin/tazobactam: a systematic review and meta-analysis. Clin Infect Dis.2013;56(2):272-82. doi: 10.1093/cid/cis857.

15. Dulhunty JM, Roberts JA, Davis JS, Webb SA, Bellomo R, Gomersall $C_{1}$ et al. Continuous infusion of beta-lactam antibiotics in severe sepsis: a multicenter double-blind, randomized controlled trial. Clin Infect Dis. 2013;56(2):236-44. doi: 10.1093/cid/cis856.

16. Lewis PO, Jones A, Amodei RJ, Youssef D. Continuous Infusion Ampicillin for the Outpatient Management of Enterococcal Endocarditis: A Case Report and Literature Review. Journal of Pharmacy Practice. 2020;33(3):392-394. doi:10.1177/0897190018804964
17. Gil-Navarro, MV, Lopez-Cortes, LE, Luque-Marquez, R, GalvezAcebal, J, de Alarcon-Gonzalez, A. Outpatient parenteral antimicrobial therapy in Enterococcus faecalis infective endocarditis. J Clin Pharm Ther. 2018; 43: 220- 223. doi: 10.1111/ jcpt. 12635

18. Parsonson $F$, Legg A, Halford M, McCarthy K. Contemporaneous management of ampicillin infusions in the outpatient setting through the use of therapeutic drug monitoring. International J Antimicrob Agents. 2020; 55: 105975. doi: 10.1016/j. ijantimicag.2020.105975.

19. USP 797 Guidebook to pharmaceutical compounding sterile preparations. In USP Pharmacists Pharmacopeia 2008-2009.2nd ed. Bethesda MD. American Society of Health-System Pharmacists 2008

20. Manning L, Wright $\mathrm{C}$, Ingram PR, Whitmore TJ, Heath $\mathrm{CH}$, Manson I, et al. Continuous infusions of meropenem in ambulatory care: clinical efficacy, safety and stability. PLoS One. 2014;9(7):e102023. doi: 10.1371/journal.pone.0102023. eCollection 2014

21. González-Ramallo VJ, Mirón-Rubio M, Mujal A, Estrada O, Forné C, Aragón B, et al. Costs of outpatient parenteral antimicrobial therapy (OPAT) administered by Hospital at Home units in Spain. Int J Antimicrob Agents. 2017;50(1):114-118. doi: 10.1016/j. ijantimicag.2017.02.017..

22. Chapman AL, Dixon S, Andrews D, Lillie PJ, Bazaz R, Patchett JD. Clinical Efficacy and cost-effectiveness of outpatient parenteral antibiotic therapy (OPAT): a UK perspective. Clinical Efficacy and cost-effectiveness of outpatient parenteral antibiotic therapy (OPAT): a UK perspective. I Antimicrob Chemother. 2009;64:1316:2464. doi: 10.1093/jac/dkp343.

23. Hitchcock J, Jepson AP, Main J, Wickens HJ. Establishment of an outpatient and home parenteral antimicrobial therapy service at a London teaching hospital: a case series. J Antimicrobial Chemother. 2009; 64:630-464. doi: 10.1093/jac/dkp212.

24. Mirón-Rubio M, González-Ramallo V, Estrada-Cuxart O, SanromaMendizábal P , Segado-Soriano A, Mujal-Martínez $A$, et al. Intravenous antimicrobial therapy in the hospital-at-home setting: data from the Spanish Outpatient Parenteral Antimicrobial Therapy Registry. Future Microbiol.2016; 11(3):375-90. doi: 10.2217/ fmb.15.141.

25. MacKenzie M, Rae N, Nathwani D. Outcomes from global adult outpatient parenteral antimicrobial therapy programmes: a review of the last decade. Int J Antimicrob Agents. 2014;43(1):7-16. doi: 10.1016/j.jjantimicag.2013.09.006.

26. Barr DA, Semple L, Seaton RA. Outpatient parenteral antimicrobial therapy (OPAT) in a teaching hospital-based practice: a retrospective cohort study describing experience and evolution over 10 years. Int J Antimicrob Agents. 2012;39(5):407-13. doi: 10.1016/j.jjantimicag.2012.01.016.

27. Voumard R, Gardiol C, André P, Arensdorff L, Cochet C, BoillatBlanco $N$, et al. Efficacy and safety of continuous infusions with elastomeric pumps for outpatient parenteral antimicrobial therapy (OPAT): an observational study. J Antimicrob Chemother. 2018;73(9):2540-2545. doi: 10.1093/jac/dky224. 